Is early intervention for psychosis a waste

\title{
of valuable resources?
}

\author{
ANTHONY PELOSI / MAX BIRCHWOOD
}

Edited and introduced by Mary Cannon, Kwame McKenzie and Andrew Sims.

\section{INTRODUCTION}

The concept of early intervention for psychosis has received much attention in recent years. The experience of pioneer services in the USA and Australia has convinced the UK Government to set aside millions of pounds to make dedicated early intervention teams an integral part of standard mental health services across the country. Other governments are set to follow suit. The rationale for early intervention is that there is a higher success rate if psychotic symptoms are treated early than if they are treated after they have been present for some time. It is also claimed that interventions early in the course of the illness can decrease the psychosocial impact of a psychotic illness that leads to secondary disability. But have these assertions been empirically demonstrated? Do such services simply take valuable resources, both in terms of funding and staff, from an already-overstretched mental health system, or do they change the trajectory of the disease process in a fundamental way? Dr Max Birchwood, Director of the Birmingham Early Intervention Service, and Dr Anthony Pelosi, consultant psychiatrist with a 'generic' community service in East Kilbride, Scotland, debate this issue.

\section{FOR}

A group of self-confessed evangelists has successfully encouraged the establishment of specialised teams for early treatment of psychotic disorders in several developed countries (Edwards \& McGorry, 2002). Who could argue with their view that every troubled young person who may be developing a devastating chronic psychosis should be given immediate and specific treatment? Who could possibly be opposed to intensive input from highly staffed teams during the first few years of schizophrenia or manic depression? The answer to these questions is: everybody with a rudimentary knowledge of epidemiology and every experienced clinician.

Helene Verdoux and her colleagues have used the approach of the early intervention movement to illustrate the inconvenient fact that the positive predictive value of any test is dependent on the prevalence of the condition to which it applies. This means that for every individual who is appropriately treated during a prodromal phase of, for example, schizophrenia there are many more, with similar clinical features, who will never develop this uncommon illness. Vulnerable patients will unnecessarily receive powerful antipsychotic medication and equally powerful and potentially dangerous specific psychotherapy, making it inevitable that these identification and treatment programmes for people at high risk of psychosis will do more harm than good. Warnings such as these (Verdoux, 2001) have been dismissed as negative criticism by exponents of early intervention without any effective counter-arguments.

Within the British health care system, uncertainties in the early management of severe mental disorders can be tackled by comprehensive locality-based psychiatric services that have good links with family doctors. All patients of all ages with nonspecific features of mental illness should be given high-quality care appropriate to their current clinical and social needs. If a major psychosis declares itself, this will lead to prompt or, if the general practitioner considers it necessary, immediate reassessment by the multi-disciplinary mental health team.

Amazingly, early intervention projects in the UK are excluding themselves from this difficult but vital part of community psychiatry. They only become involved when there is an obvious psychosis - so long as the patient is not middle-aged or old, and only for an arbitrary 'critical period' of a few years. These teams claim to have special skills and yet their papers and book chapters on intensive early intervention simply describe some basic aspects of good practice in the management of psychotic disorders (Birchwood et al, 2000; Edwards \& McGorry, 2002). These publications read like extended essays by a candidate for the MRCPsych examination - and they would not even receive high marks since they gloss over the ethical and clinical quandaries that are faced when compulsory treatment has to be considered.

Early intervention practitioners not only claim special technical skills. They also have convinced themselves that ordinary mental health professionals are 'impatient and crude' in their use of medicine and 'neglect ... psychotherapeutic and psychosocial aspects of treatment'. This, they maintain, arises partly from '. . . a lack of empathy with the predicament of the person experiencing the emerging illness' (McGorry, 2000). It is undeniable that many patients in the early (and middle, and late) stages of a psychotic illness do not receive good care from routine services in the UK. Most failures of service delivery are due to inadequate numbers of appropriately trained clinicians. It is difficult not to feel angry when staff shortages are worsened by recruitment raids from early intervention projects. These teams should explain to the rest of us - and especially service users - how their greater empathy is compatible with giving up on patients and passing them back to hard-pressed local services after only 3 years of a chronic illness.

The enthusiasts of the early intervention movement are undoubtedly well-meaning in their desire to prevent chronic illness and minimise disability. However, their wishful thinking has misled health policymakers who are diverting resources to specialised teams, making it even more 
difficult to provide decent care to people with severe and enduring mental disorders. It takes more than leisurely work with highly selected patients for a few years to have any meaningful impact on the suffering caused by major mental illnesses. These least industrious of all evangelists should stop kidding themselves and bring their precious and much needed skills back into the mainstream of mental health care.

Anthony J. Pelosi Consultant Psychiatrist, Hairmyres Hospital, East Kilbride G75 8RG, UK. E-mail: anthony.pelosi@lanpct.scot.nhs.uk

\section{AGAINST}

Rethink, a UK mental health charity, recently launched its campaign 'Reaching People Early' (http://www.rethink.org/ reachingpeopleearly) to bring to wider attention the poor state of services for young people with severe mental illness. They describe a catalogue of concerns. On average, there is a delay of 12 months between the onset of positive symptoms and first treatment (Norman \& Malla, 2001). Some of this delay occurs because of problems at the interface of primary and secondary care, including the lack of an 'assertive' response when the diagnosis is first raised. Long delays increase the chance of use of the Mental Health Act 1983 (which is frequent at the first episode, being used in the majority of cases in many settings) and its use breeds service disengagement - in many routine service settings over $50 \%$ are lost to services within 12 months (McGovern et al, 1994). Early use of the Mental Health Act increases the likelihood of its further use, with young African and African-Caribbean males particularly at risk. Suicide remains high and young people in the early phase are particularly at risk. Rethink points out that the incidence of schizophrenia begins to rise during the 15- to 18-year age range and does not respect the often impermeable service boundaries between child and adolescent and adult mental health services. Young people surveyed by Rethink found services stigmatising, therapeutically pessimistic and youth-insensitive (access to employment and training are high on their priorities). Would we be happy with our children receiving care from our services? My impression is that many mental health professionals are also dissatisfied with the current quality of care but provide a caring and professional service within the constraints that service pressure and resources allow. These are reasons enough to 'Rethink' our services to young people with severe mental illness. Imagine the uproar if, instead of early psychosis, these observations were made about youth cancer services.

Is early intervention a waste of valuable resources? Presumably the issue is not the extra resources for the people with severe mental illness that is of concern, but providing them early. On this issue, of course, we are already making a choice: what we practise now is late intervention (and, Rethink would argue, low-intensity, haphazard and coercive intervention). It is true that the evidence base for late intervention in psychosis has never been established (the same can be said of much of what we currently take for granted - admission, out-patients, forensic services, rehabilitation. .. ) but this is to miss the point. Surely our aim at this stage is to develop services that young people from all ethnic groups will engage with willingly: without this, even our best treatments have no chance of working and we risk getting caught up in a cycle of coercion. Engagement and service satisfaction are key outcomes. Success in persuading governments to invest in young people with severe mental illness does not mean that this will be at the expense of those with enduring psychoses. All groups are important: this is not an early $v$. late debate.

The rationale for early intervention is overwhelming. A great deal is now known about the long-term trajectories of psychoses and their biological and psychosocial influences. Delay in first treatment is robustly linked with poor early outcome (Norman \& Malla, 2001) and long-term follow-up studies show clearly that the outcome at 2-3 years strongly predicts outcome 20 years later (Harrison et al, 2001) and that disability 'plateaus' by this time: the early phase is indeed a critical period (Birchwood et al, 1997). Intensive services (e.g. assertive community treatment, rehabilitation) kick in far too late, long after the horse has bolted: we need to ensure that our best treatments and service configurations are available early.

There are existing and ongoing early intervention studies from Norway/USA ('TIPS'; Johannessen et al, 2001), Denmark ('OPUS'; Nordentoft et al, 2000), the European Union ('EPOS'; European multicentre Prediction of Schizophrenia study: no published results yet available) and the UK ('SOCRATES'; Lewis et al, 2002) which will inform us about what kind of early detection/treatment is best. For example, early results from the TIPS study show that the duration of untreated psychosis can be dramatically reduced by a public education campaign (from 118 to 20 weeks) leading to improvement in service engagement and decreased use of compulsory detention. Data from SOCRATES show that cognitive-behavioural therapy at the first episode combined with drugs improves recovery at 12 months.

The UK Government's investment in new services for early psychosis is welcome and is intended to address the problems raised by Rethink (see http://www.doh. gov.uk/mentalhealth/implementationguide. htm for the policy implementation guidelines); they provide, for example, for a case manager to be appointed for, and remain with, every case of actual or possible psychosis, with a staff:client ratio of 1:12. The new services will also provide an important opportunity to address key research questions, and the research infrastructure provided by the new National Institute of Mental Health UK will provide a unique opportunity to conduct major large-scale research in this area. A waste of valuable resources? The UK is in a period of unprecedented (promised) growth in community mental health services for those with the most severe mental illnesses and this extra investment is where it should be - directed at the most vulnerable groups at a critical period.

Max Birchwood Birmingham Early Intervention Service, Northern Birmingham Mental Health Trust, Harry Watton House, 97 Church Lane, Aston, Birmingham B6 5UG, UK. E-mail: max.birchwood@nbmht.nhs.uk

\section{REFERENCES}

Birchwood, M., McGorry, P. \& Jackson, H. (1997) Early intervention in schizophrenia. British Journal of Psychiatry, 170, 2-5.

_ , Fowler, D. \& Jackson, C. (eds) (2000) Early Intervention in Psychosis. A Guide to Concepts, Evidence and Interventions. Chichester: John Wiley \& Sons.

Edwards, J. \& McGorry, P. D. (2002) Implementing Early Intervention in Psychosis. A Guide to Establishing Early Psychosis Services. London: Martin Dunitz.

Harrison, G., Hopper, K., Craig, T., et al (2001) Recovery from psychotic illness: a 15- and 25-year international follow-up study. British Journal of Psychiatry, I78, 506-517. 
Johannessen, J. O., McGlashan, T. H., Larsen, T. K., et al (200I) Early detection strategies for untreated first-episode psychosis. Schizophrenia Research, 5I, 39-46.

Lewis, S., Tarrier, N., Haddock, G., et al (2002)

Randomised controlled trial of cognitive-behavioural therapy in early schizophrenia: acute-phase outcomes. British Journal of Psychiatry, I8I (suppl. 43), s91-s97.

McGorry, P. (2000) The scope for preventative strategies in early psychosis. Logic, evidence and momentum. In Early Intervention in Psychosis. A Guide to Concepts, Evidence and Interventions (eds M. Birchwood
D. Fowler \& C. Jackson), pp. 3-27. Chichester: John Wiley \& Sons.

McGovern, D., Hemmings, P. \& Cope, R. (1994)

Long-term follow-up of young Afro-Caribbean Britons and White Britons with a first admission diagnosis of schizophrenia. Social Psychiatry and Psychiatric Epidemiology, 29, 8-19.

Nordentoft, M., Jeppesen, P., Abel, M., et al (2002) OPUS study: suicidal behaviour, suicidal ideation and hopelessness among patients with first-episode psychosis. One-year follow-up of a randomised controlled trial. British Journal of Psychiatry, I8I (suppl. 43), s98-s106.

Norman, R. M. \& Malla, A. K. (200I) Duration of untreated psychosis: a critical examination of the concept and its importance. Psychological Medicine, 31 $38 I-400$.

Verdoux, H. (200I) Have the times come for early intervention in psychosis? Acta Psychiatrica Scandinavica, 103, 321-322. 